\title{
Trends in very early discharge from hospital for newborns under midwifery care in Ontario from 2003 to 2017: a retrospective cohort study
}

\author{
Elizabeth K. Darling RM PhD, Glenda Babe MA, Carla Sorbara RM MSc, Richard Perez MSc
}

Abstract

Background: Very early discharge from hospital is an element of Ontario midwifery care. Our aim in the present study was to describe the frequency of very early hospital discharge for newborns in Ontario midwifery care over time.

Methods: We conducted a retrospective population-based cohort study, including all midwife-attended singleton term cephalic newborns delivered by spontaneous vaginal birth at Ontario hospitals between April 2003 and February 2017. Our primary outcome was very early hospital discharge ( $<6 \mathrm{~h}$ after birth) for newborns. Secondary outcomes were pediatric consultation before hospital discharge, phototherapy before hospital discharge and readmission for treatment of jaundice. We used generalized linear mixed models to estimate the relation between maternal, neonatal and hospital factors and very early discharge, while accounting for clustering by hospital.

Results: The study cohort included 101852 newborns born at 89 hospitals. Between 2003/04 and 2016/17, the unadjusted rate of very early discharge decreased from $34.3 \%$ to $30.7 \%$. This trend was not significant after adjustment for covariates (odds ratio 1.0 , $95 \%$ confidence interval 0.99-1.0). Unadjusted rates of pediatric consultation, phototherapy and readmission for jaundice all rose slightly over the study period. Hospital-specific risk-adjusted frequencies of very early discharge ranged from $5 \%(n=1479)$ to $83 \%$ $(n=3459)$ across the 75 Ontario hospitals with at least 100 newborns included in the study cohort.

Interpretation: Hospital-level factors contributed to the observed decrease in crude rates of very early discharge for midwifery clients. Wide variation in these rates across Ontario hospitals points to room for improvement to make more efficient use of health care resources by promoting optimal levels of very early discharge.

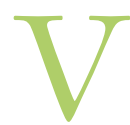

ery early discharge from hospital following birth has been an element of the Ontario midwifery model since midwifery was regulated and funded, in $1994 .^{1,2}$ Ontario midwives autonomously care for people experiencing normal pregnancy and birth, although some midwifery clients develop conditions in pregnancy or labour that necessitate consultation with or transfer of care to a physician.

Midwifery clients who have uncomplicated births are eligible for discharge within 3-4 hours of birth. ${ }^{3}$ The attending midwife conducts a complete newborn examination before hospital discharge. Care in the first week postpartum is then provided in the home, with the first visit typically occurring within 24 hours of the birth. ${ }^{2,4}$ Postpartum home visits include breast-feeding support, and the Ontario midwifery model has shown good maternal and neonatal outcomes, including high rates of breast-feeding. ${ }^{4-7}$ Research shows that, with adequate antenatal care and good follow-up, early discharge yields good parent satisfaction. ${ }^{8}$ Furthermore, early hospital discharge for midwife-attended births represents a cost savings to the health care system.

Over time, a variety of policy and practice changes may have influenced very early discharge rates for Ontario midwifery clients..$^{9,10}$ One example is Ontario's 2003 policy of offering a 60-hour postpartum stay to anyone who wanted it. ${ }^{10}$ Another factor is the introduction of universal neonatal bilirubin screening, which typically is performed at 24 hours of age or later., ${ }^{9,11}$ Ontario gradually adopted universal bilirubin screening following publication of the Canadian Paediatric Society's 2007 hyperbilirubinemia guideline $e^{9,12}$ and

Competing interests: None declared.

This article has been peer reviewed.

Correspondence to: Elizabeth Darling, darlinek@mcmaster.ca

CMAJ Open 2020. DOI:10.9778/cmajo.20190165 
then more actively promoted it through a 2013 provincial hyperbilirubinemia Quality-Based Procedure. ${ }^{13}$

Anecdotal evidence suggests that the proportion of midwifery clients being discharged very early has decreased in some Ontario hospitals. The aim of our study was to describe the frequency of very early hospital discharge for newborns in Ontario midwifery care over time.

\section{Methods}

\section{Design, setting and population}

We conducted a retrospective population-based cohort study of all live-born term newborns delivered by spontaneous vaginal birth in Ontario hospitals between Apr. 1, 2003, and Feb. 28, 2017, who were attended by midwives. Our first objective was to determine whether the frequency of very early hospital discharge in this population changed over time. The second objective was to compare hospital-specific riskadjusted frequencies of very early discharge. The study start date was based on when gestational age became available in our data sources.

We excluded births that occurred before 37 weeks' gestation, multiple births and noncephalic presentations because these newborns are unlikely to be discharged very early. We excluded cases for which the time of birth was missing and those where the date and time of discharge were recorded to be before the birth. We also excluded all newborns whose "birth" admission was at 1 of 2 pediatric hospitals in the province because these hospitals do not conduct births and newborns admitted to these hospitals would not be candidates for very early hospital discharge.

\section{Data sources}

The study was conducted at ICES, an independent, nonprofit research institute with authority under Ontario's health information privacy law to collect and analyze health care and demographic data, without consent, for health system evaluation and improvement. We used the following data sources: the Discharge Abstract Database, ${ }^{14}$ the Registered Persons Database, ${ }^{15}$ the Ontario Hospital Insurance Plan database, ${ }^{15}$ and ICES's MOMBABY and ONMARG data sets. ${ }^{16}$ Data were linked using unique encoded identifiers. Further details about each data source are provided in Appendix 1, Supplemental Table S1 (available at www.cmajopen.ca/content/8/2/ E462/suppl/DC1).

We identified our cohort using linked maternal and newborn records in MOMBABY and used service provider type codes captured in the Discharge Abstract Database (Appendix 1, Supplemental Table S2) to determine whether a registered midwife was one of the care providers during the intrapartum hospital admission.

\section{Outcomes}

Our primary outcome was very early discharge from hospital for the newborn, defined as discharge less than 6 hours after birth. We created this dichotomous variable by calculating length of stay using time of birth and time of hospital dis- charge. We selected less than 6 hours based on clinical expertise and confirmed it by examining the distribution of length of stay in the cohort.

We hypothesized that changes in hyperbilirubinemia screening practices might drive changes in newborn length of stay, and therefore examined 3 related secondary outcomes: pediatric consultation before hospital discharge, phototherapy before hospital discharge and readmission for treatment of jaundice (see Appendix 1, Supplemental Table 2 for the codes used to create these variables).

Maternal and neonatal covariates were selected a priori for clinical reasons, ${ }^{17,18}$ and hospital and policy factors were based on hypothesized associations. A priori covariates included maternal factors (parity [primiparous v. multiparous], rural residence [based on maternal postal code and determined with Postal Code ${ }^{\mathrm{OM}}$ Conversion File Plus ${ }^{19}$, material deprivation [measured in quintiles by means of the 2016 Ontario Marginalization Index ${ }^{20}$, diabetes and hypertension), newborn factors (gestational age category [37-38 wk, 39-40 wk, $\geq 41 \mathrm{wk}$ ), hospital factors (annual birth volume $[\leq 500,501-$ $1000,1001-2000, \geq 2001$ ], proportion of total births attended by midwives $<10 \%, 10 \%-20 \%,>20 \%$ ) and policy factors (the Canadian Paediatric Society guidelines [2007 onward] ${ }^{9,12}$ and Ontario's hyperbilirubinemia Quality-Based Procedure [2013 onward $]^{13}$ ). We also calculated the proportion of births conducted by a physician (see Appendix 1, Supplemental Table S2 for codes).

\section{Statistical analysis}

We calculated the crude frequency of each outcome by fiscal year and graphed trends over time. We conducted a secondary analysis of the primary outcome after excluding births conducted by a physician.

We used generalized linear mixed models to estimate the relation between covariates and the primary outcome (very early discharge), and to calculate odds ratios. Fixed effects in the model included maternal factors (parity, rural residence, material deprivation, diabetes, hypertension, physicianconducted birth), newborn factors (gestational age category) and hospital factors (annual birth volume, proportion of total births attended by midwives). We used a fixed-effect fiscal year variable to account for a possible underlying time trend. We accounted for the nested relation of newborns within hospitals (i.e., clustering) by including hospital number as a random effect in the model. We imputed missing values using the discriminant function method and conducted a sensitivity analysis to compare model results with imputation to include cases with missing values and to exclude cases with missing values.

We also calculated overall adjusted percentages of very early discharge for each hospital by multiplying hospital specific predicted/expected ratios by the overall rate of very early discharge for the population. Expected values were obtained from a model using the average of hospital-specific intercepts, and predicted values were obtained from a similar model using the individual hospital-specific intercepts rather than the average. Analyses were conducted with SAS version 9.4 (SAS Institute). 


\section{Ethics approval}

The use of data in this project was authorized under section 45 of Ontario's Personal Health Information Protection Act, which does not require review by a research ethics board.

\section{Results}

Between 2003/04 and 2016/17, there were 1852480 linkable births in the MOMBABY data set, of which 1749628 were excluded (stillbirth in 1320 cases; multiple birth in 64 284; gestational age < 37 wk in 112 116; baby's date of death was before date of birth in 257; midwife did not provide intrapartum care in 1545 040; cesarean, forceps, vacuum or breech birth in 24 503; other noncephalic presentation in 1872; time of birth missing in 944; date and time of discharge were before birth in 130; and admission at pediatric hospital in 162). The study cohort thus included 101852 newborns, born across 89 hospitals.

Table 1 shows the characteristics of the included newborns. Newborns discharged from hospital within 6 hours of birth were more likely to be born to an older, multiparous woman, and less likely to be born before 39 weeks' or after 40 weeks' gestation, to live in a rural area or a neighbourhood with high levels of material deprivation, or to be born to a woman with diabetes or hypertension.

Figure 1 shows the crude rate of very early discharge for all births in the study cohort and for just those conducted by midwives $(n=86412)$ over the study period. There was a small absolute decrease in this rate over time, from $34.3 \%$ in $2003 / 04$ to $30.7 \%$ in $2016 / 17$. About $16 \%$ of births were conducted by a physician. After physician-conducted births were excluded, very early discharge was roughly $3 \%$ more frequent but followed a similar trend. Figure 2 shows the overall crude rates of pediatric consultation before hospital discharge, phototherapy before hospital discharge and readmission for jaundice over this same period; the rates of all 3 outcomes rose slightly.

Table 2 shows the results of the generalized linear mixed model. Publication dates of hyperbilirubinemia policies were not associated with statistically significant changes in very early discharge, so they were not included in the final model. After adjusting for covariates, we found no underlying temporal trend in the rate of very early discharge (odds ratio 1.0, $95 \%$ confidence interval $0.99-1.0$ ). Multiparity was associated with higher rates of very early discharge, whereas rural residence and being in the lowest 2 material deprivation quintiles were associated with lower rates. Additional variation was associated with hospital characteristics: newborns born at hospitals with more than 1000 births per year or hospitals with a higher proportion of midwife-attended births were less likely to be discharged very early.

We found wide variation in the frequency of very early discharge across hospitals. The hospital-specific riskadjusted frequency of very early discharge ranged from $5 \%$ $(n=1479)$ to $83 \%(n=3459)$ across the 75 hospitals with at least 100 newborns included in the cohort (Figure 3). For each hospital, we examined changes around the times that

\begin{tabular}{|c|c|c|}
\hline \multicolumn{3}{|c|}{$\begin{array}{l}\text { Table 1: Baseline characteristics of singleton term cephalic } \\
\text { newborns in midwifery care delivered by spontaneous vagina } \\
\text { birth in Ontario, } 2003 / 04 \text { to } 2016 / 17 \text {, by newborn length of stay }\end{array}$} \\
\hline \multirow[b]{2}{*}{ Characteristic } & \multicolumn{2}{|c|}{$\begin{array}{l}\text { Length of stay, } \mathrm{h} \text {; } \\
\text { no. }(\%) \text { of newborns }\end{array}$} \\
\hline & $\begin{aligned} & <6 \\
n= & 32447\end{aligned}$ & $\begin{aligned} & \geq 6 \\
n= & 69405\end{aligned}$ \\
\hline \multicolumn{3}{|l|}{ Maternal age, yr } \\
\hline$<20$ & $385(1.2)$ & $1601(2.3)$ \\
\hline $20-24$ & $2890(8.9)$ & $8202(11.8)$ \\
\hline $25-29$ & $9273(28.6)$ & $21810(31.4)$ \\
\hline 30-34 & 13416 (41.3) & 26352 (38.0) \\
\hline 35-39 & $5755(17.7)$ & $10094(14.5)$ \\
\hline$\geq 40$ & $728(2.2)$ & $1346(1.9)$ \\
\hline \multicolumn{3}{|l|}{ Maternal parity } \\
\hline Multiparous & $22091(68.1)$ & $40182(57.9)$ \\
\hline Primiparous & 10356 (31.9) & $29223(42.1)$ \\
\hline \multicolumn{3}{|l|}{ Gestational age, wk } \\
\hline $37-38$ & 5339 (16.4) & 12876 (18.6) \\
\hline $39-40$ & 20945 (64.5) & $42842(61.7)$ \\
\hline$\geq 41$ & $6143(18.9)$ & $13660(19.7)$ \\
\hline Missing & $20(0.1)$ & $27(<0.1)$ \\
\hline \multicolumn{3}{|l|}{$\begin{array}{l}\text { Maternal deprivation } \\
\text { quintile* }\end{array}$} \\
\hline 1 (least deprived) & $8144(25.1)$ & $15156(21.8)$ \\
\hline 2 & $7171(22.1)$ & $14491(20.9)$ \\
\hline 3 & $6082(18.7)$ & 13208 (19.0) \\
\hline 4 & $5480(16.9)$ & 12344 (17.8) \\
\hline 5 (most deprived) & 5025 (15.5) & 12856 (18.5) \\
\hline Missing & $545(1.7)$ & $1350(1.9)$ \\
\hline \multicolumn{3}{|l|}{ Rural residence $†$} \\
\hline No & $29376(90.4)$ & 60525 (87.2) \\
\hline Yes & $3040(9.4)$ & $8844(12.7)$ \\
\hline Missing & $31(0.1)$ & $36(<0.1)$ \\
\hline \multicolumn{3}{|l|}{ Maternal risk factors } \\
\hline Diabetes & $154(0.5)$ & $1453(2.1)$ \\
\hline Hypertension & $247(0.8)$ & $1896(2.7)$ \\
\hline Physician-conducted birth & $2144(6.6)$ & $13296(19.2)$ \\
\hline \multicolumn{3}{|c|}{$\begin{array}{l}\text { *Measured with the } 2016 \text { Ontario Marginalization Index. } .^{20} \\
\text { †Based on maternal postal code and determined with Postal Code }{ }^{\text {om }} \text { Conversion } \\
\text { File Plus. }{ }^{19}\end{array}$} \\
\hline
\end{tabular}

new hyperbilirubinemia guidelines were released (2007 and 2013). There were no consistent patterns in the rate of very early discharge in relation to these policy changes. In the 40 hospitals where midwives conducted at least 10 births in both the first and last years of the study, changes in the unadjusted frequency of very early discharge over the study period ranged from an increase of $21 \%$ to a decrease of $39 \%$. 


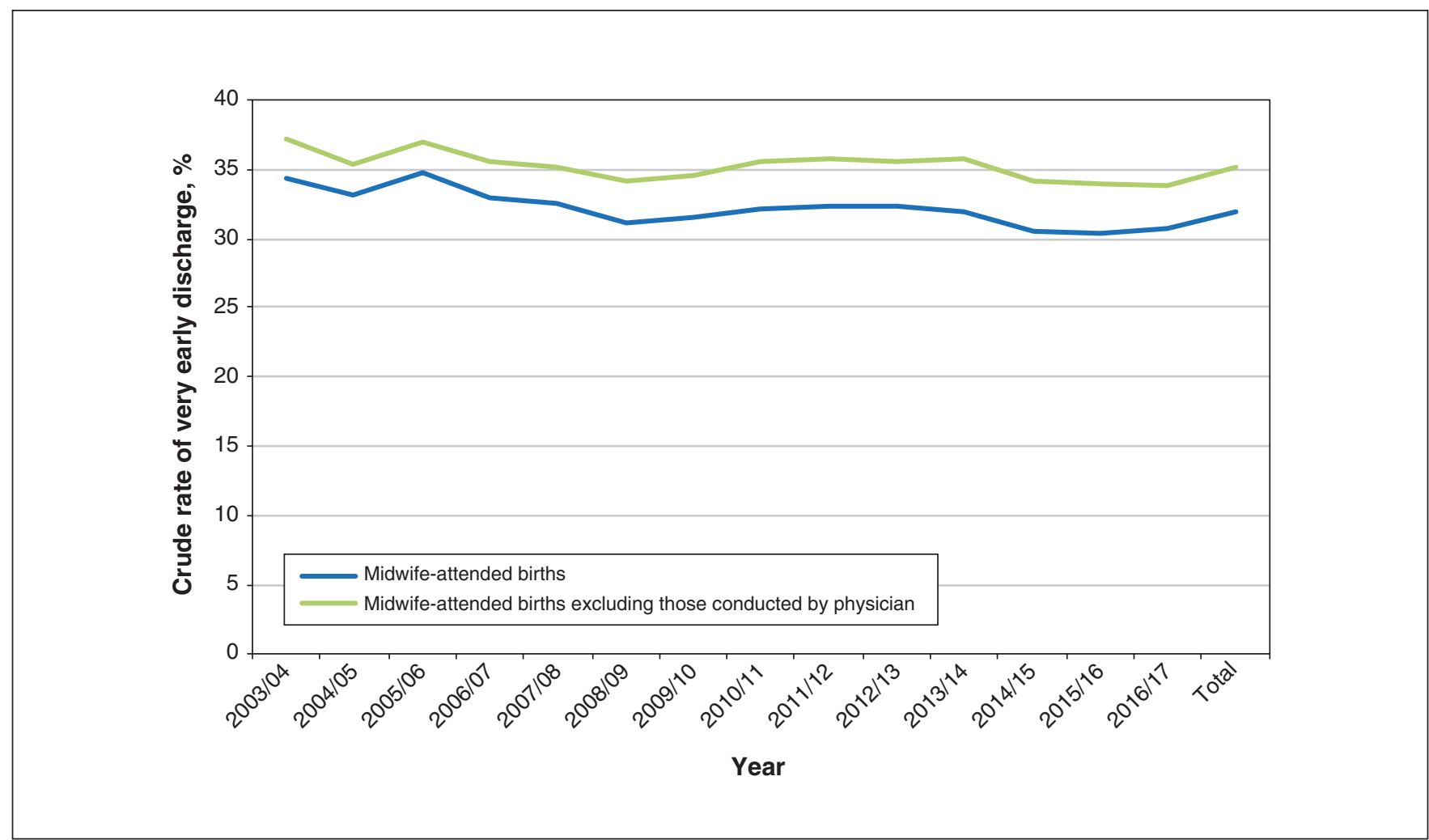

Figure 1: Unadjusted rates of very early discharge $(<6 \mathrm{~h}$ after birth) from hospital following spontaneous vaginal birth for singleton term cephalic newborns in midwifery care in Ontario, 2003/04 to 2016/17.

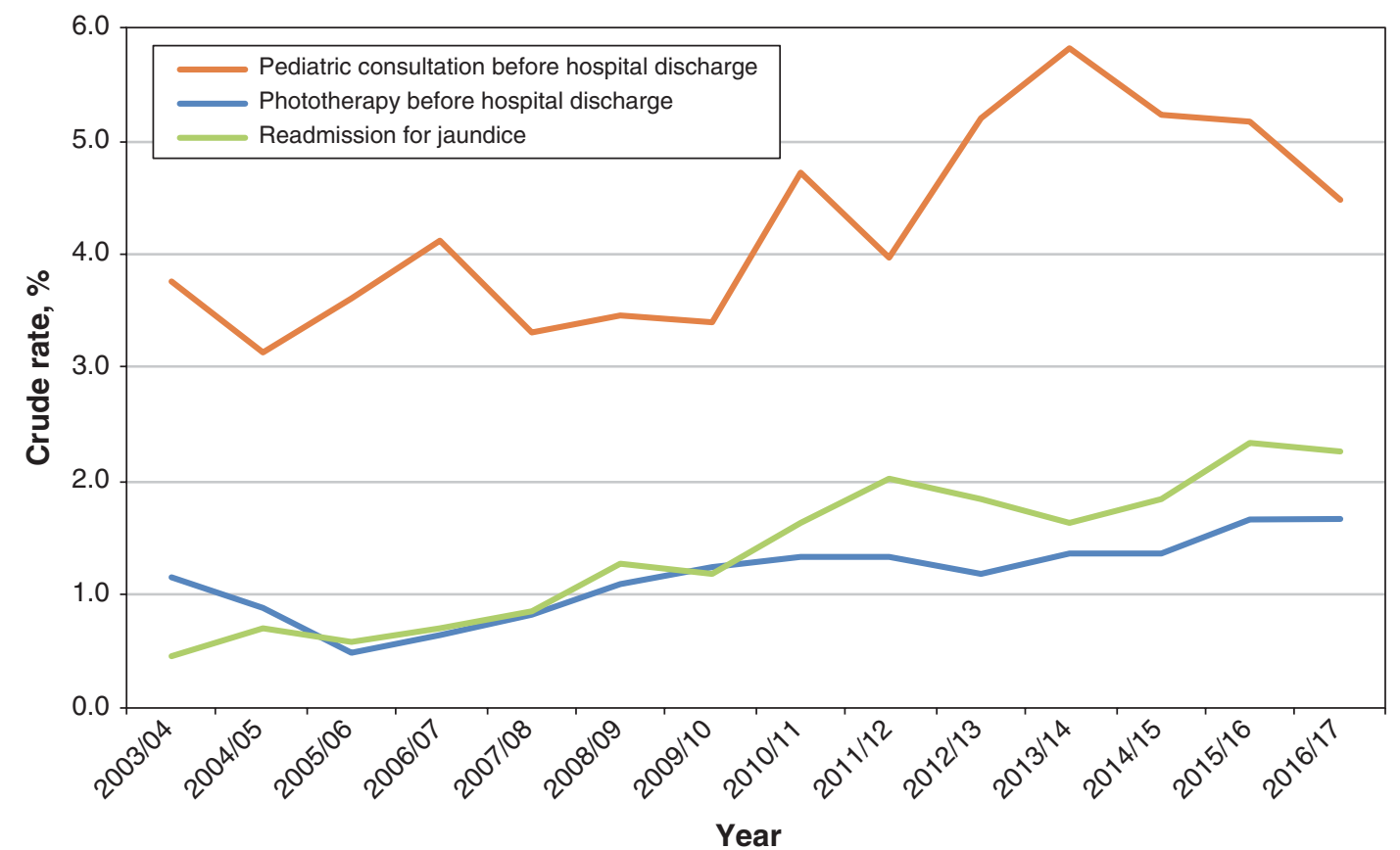

Figure 2: Unadjusted rates of pediatric consultation before hospital discharge, phototherapy before hospital discharge and readmission for jaundice, 2003/04 to 2016/17. 


\section{Table 2: Generalized linear mixed model of very early} discharge ( $<6 \mathrm{~h}$ after birth)

\begin{tabular}{|c|c|c|}
\hline Variable & $\begin{array}{c}\text { Crude rate } \\
\text { of very early } \\
\text { discharge, \% }\end{array}$ & OR $(95 \% \mathrm{Cl})$ \\
\hline Year & - & $1.00(0.99-1.01)$ \\
\hline \multicolumn{3}{|l|}{ Parity } \\
\hline Primiparous & 26.2 & Reference \\
\hline Multiparous & 35.5 & $1.67(1.62-1.72)$ \\
\hline \multicolumn{3}{|l|}{ Rural residence } \\
\hline No & 32.7 & Reference \\
\hline Yes & 25.6 & $0.83(0.78-0.88)$ \\
\hline \multicolumn{3}{|c|}{ Material deprivation quintile } \\
\hline 1 (least deprived) & 34.9 & Reference \\
\hline 2 & 33.1 & $1.00(0.96-1.04)$ \\
\hline 3 & 31.4 & $0.97(0.93-1.02)$ \\
\hline 4 & 30.6 & $0.93(0.89-0.98)$ \\
\hline 5 (most deprived) & 28.1 & $0.83(0.80-0.87)$ \\
\hline \multicolumn{3}{|l|}{ Gestational age, wk } \\
\hline $39-40$ & 32.8 & Reference \\
\hline $37-38$ & 29.3 & $0.91(0.87-0.94)$ \\
\hline$\geq 41$ & 31.0 & $0.95(0.91-0.99)$ \\
\hline \multicolumn{3}{|c|}{$\begin{array}{l}\text { Volume of births per year at } \\
\text { hospital }\end{array}$} \\
\hline$>2000$ & 35.9 & Reference \\
\hline $1001-2000$ & 27.1 & $1.05(0.96-1.15)$ \\
\hline $501-1000$ & 23.3 & $2.31(2.02-2.63)$ \\
\hline$\leq 500$ & 27.4 & $2.01(1.66-2.43)$ \\
\hline \multicolumn{3}{|c|}{$\begin{array}{l}\% \text { of births attended by } \\
\text { midwives at hospital }\end{array}$} \\
\hline$<10$ & 37.1 & Reference \\
\hline $10-20$ & 32.0 & $0.91(0.86-0.97)$ \\
\hline$>20$ & 26.7 & $0.88(0.81-0.96)$ \\
\hline \multicolumn{3}{|l|}{ Maternal diabetes } \\
\hline No & 32.2 & Reference \\
\hline Yes & 9.6 & $0.22(0.19-0.27)$ \\
\hline \multicolumn{3}{|l|}{ Maternal hypertension } \\
\hline No & 32.3 & Reference \\
\hline Yes & 11.5 & $0.35(0.31-0.41)$ \\
\hline \multicolumn{3}{|c|}{ Physician-conducted birth } \\
\hline No & 35.1 & Reference \\
\hline Yes & 13.9 & $0.27(0.25-0.28)$ \\
\hline
\end{tabular}

\section{Interpretation}

We found a lower-than-expected frequency of very early discharge for midwife-attended newborns born by spontaneous vaginal birth in Ontario. Although the intended model for Ontario midwifery care includes very early discharge from hospital where clinically appropriate, and midwife-attended newborns delivered by spontaneous vaginal birth are generally a low-risk cohort, less than a third of our cohort left the hospital within 6 hours of birth. We also found wide variation between hospitals in rates of very early discharge and in how these rates varied over time, even after adjustment for covariates.

Although very early discharge was not associated with the publication dates of hyperbilirubinemia guidelines, we observed temporal increases in pediatric consultation and phototherapy treatment before hospital discharge, and readmission for jaundice, which reflect midwives' clinical practice changes related to bilirubin screening. The greater observed fluctuation in pediatric consultations likely reflects challenges in accessing recommended follow-up screening after hospital discharge. Midwives can order bilirubin tests, but, in some settings, pediatric consultation became the only mechanism for midwifery clients to access outpatient bilirubin screening services following hospital discharge. The gradual decrease in pediatric consultations after 2013/14 likely reflects the creation of other mechanisms for midwifery clients to access outpatient follow-up screening. A survey of Ontario midwives showed that logistical barriers to bilirubin screening after hospital discharge have been overcome by midwives in some communities but persist for others. ${ }^{21}$

We were unable to find other publications examining very early discharge after birth in Canada. Outside of the midwifery model of care, early discharge has been defined variously as discharge on the same day as birth or within 24-48 hours. ${ }^{22-24}$ A 2012 survey of Canadian hospitals showed that the length of stay following vaginal birth decreased from 3.2 days in 1993 to 2.0 days in 2012.. ${ }^{25}$ Although the hospital length of stay for term singleton newborns delivered vaginally in Canada has decreased over time,,$^{22,26}$ outside of the context of midwifery care, very early discharge is not supported by current Canadian guidelines or service delivery models (which do not typically provide in-home early postpartum care from a primary care provider). ${ }^{24}$ As would be expected given the rates of very early discharge in our study, the rate of phototherapy before hospital discharge was lower than for nonmidwife-attended births in Ontario during the same time frame. ${ }^{11}$ Rates of readmission for jaundice in our study were similar to previously reported rates for the rest of the Ontario population between 2003 and 2011. ${ }^{11}$

The factors contributing to variation in rates of very early discharge are complex. Our finding that there was not a consistent association with the dates of publications recommending bilirubin screening makes sense given that implementation of the Canadian Paediatric Society hyperbilirubinemia guidelines occurred very gradually across Ontario hospitals, and given the variation in the ways in which hospitals operationalized screening. ${ }^{9}$

Presentation of our preliminary findings to midwives ${ }^{27}$ confirmed that hyperbilirubinemia screening is not the only factor influencing very early discharge rates. For example, 


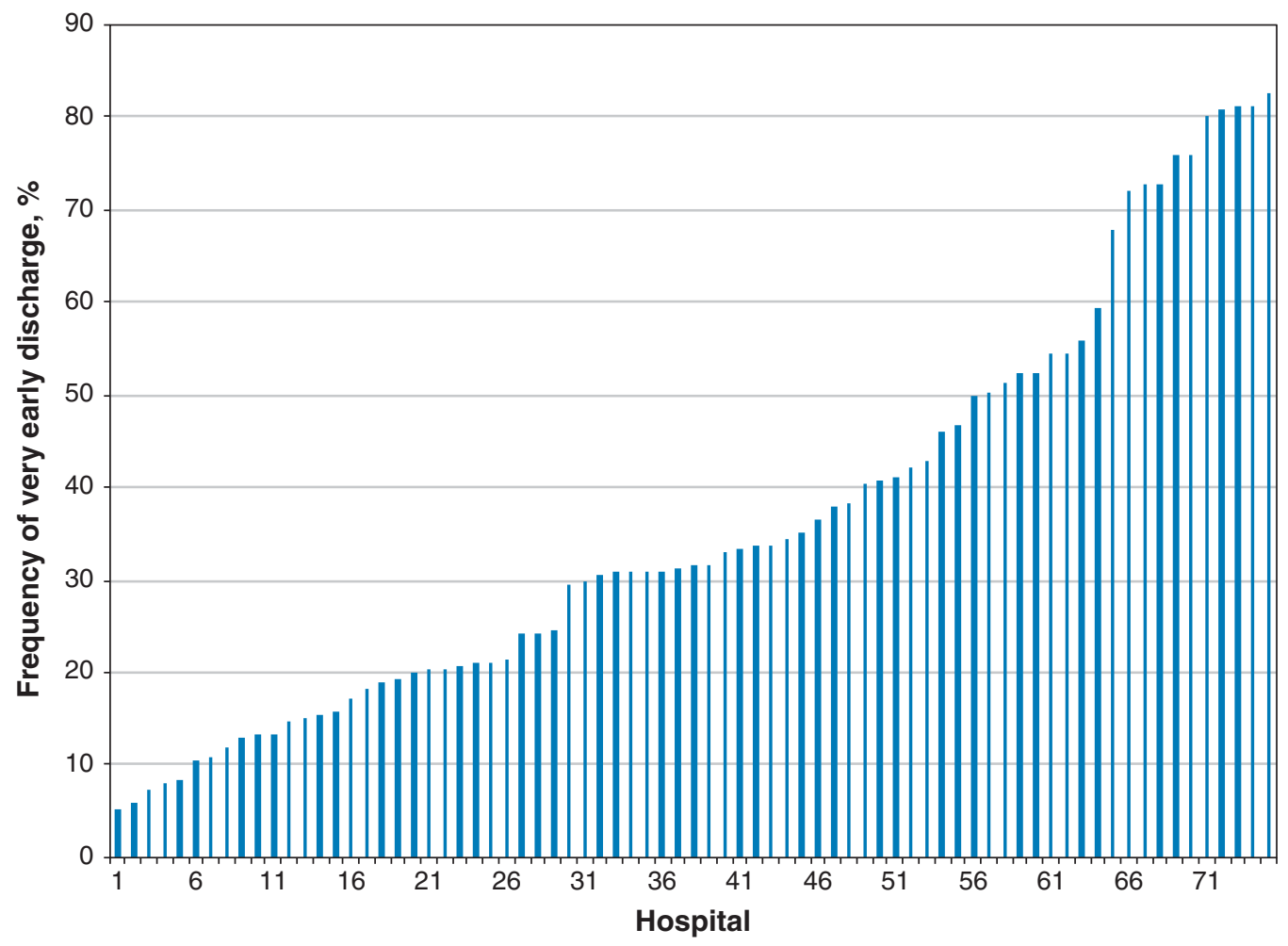

Figure 3: Hospital variation in risk-adjusted frequency of very early discharge, 2003/04 to 2016/17. Adjusted for maternal parity, maternal rural residence, maternal material deprivation, maternal diabetes, maternal hypertension, gestational age, hospital birth volume, proportion of births attended by midwives at hospital and physician-conducted birth. Excludes hospitals with fewer than 100 newborns included in the study cohort.

differences between hospital recommendations for minimum length of stay following epidural anesthesia or for ruling out newborn sepsis also likely contribute to differences in discharge practices. Variation in very early discharge rates is also influenced by other contextual factors including hospital staffing and structural capacity, budgetary constraints driving a push to shorten length of stay, and championing of clinical protocols that do not take into consideration the in-home follow-up that midwives provide. Finally, very early discharge may affect midwives' workload, and anecdotally there appears to be variation in how very early discharge is promoted by midwives to their clients.

The safety of early discharge accompanied by in-home postpartum care is supported by randomized controlled trial evidence. ${ }^{28-30}$ It is also corroborated by population-based studies of Ontario midwifery care showing very low rates of neonatal morbidity and mortality. ${ }^{31,32}$

\section{Limitations}

We examined a highly selected sample of midwife-attended term newborns delivered via spontaneous vaginal birth in hospital. The population was appropriate for the policy issue we intended to examine but limits the generalizability of our findings.
Midwifery care was integrated into the Ontario health care system in 1994, but some of the key variables needed for our study (e.g., gestational age) were not collected until 2003. Therefore, we could not examine rates of very early discharge from 1994 to 2003.

We expect that some newborns in the cohort had valid clinical reasons not to be discharged very early. However, we did not have access to full clinical records and were unable to identify neonatal clinical factors warranting a longer stay in hospital, or measure whether this proportion changed over time or varied between hospitals. In addition, there are other variables that were not considered in our model, such as time of birth.

Finally, given the limitations inherent to retrospective cohort studies, our findings do not allow us to draw any conclusions about causal factors contributing to the trend and variation in rates of very early discharge.

\section{Conclusion}

The wide variation across Ontario hospitals in frequency of very early discharge for midwifery clients points to room for improvement to make more efficient use of health care resources. Although not all midwifery clients will be appropriate for very early discharge, it is incumbent upon both 
midwives and hospitals to examine how very early discharge can be facilitated when appropriate. Ensuring midwives' involvement in developing clinical protocols that will affect their care may help contribute toward this objective. Finally, the myriad of factors driving frequencies of very early discharge are not well understood. Further research to identify the hospital, midwife and midwifery client factors that influence very early discharge could help to inform efforts to promote optimal levels of early discharge.

\section{References}

1. Kaufman KJ. The introduction of midwifery in Ontario, Canada. Birth 1991; 18:100-3.

2. Midwifery Task Force on Postpartum Visit Schedules. Guideline on postpartum visit schedules. Toronto: Association of Ontario Midwives; 2019. Available: https://www.cmo.on.ca/wp-content/uploads/2015/07/Final-PP -Newborn-visits-Standard.pdf (accessed 2020 Jan. 20).

3. Darling EK, Bennett N, Burton N, et al. Outcomes of uninsured midwifery clients in Ontario, Canada: a retrospective cohort study. Midwifery 2019;77: 24-31.

4. Postpartum/newborn visits. Toronto: College of Midwives of Ontario; 2015

5. Lutsiv O, Pullenayegum E, Foster G, et al. Women's intentions to breastfeed: a population-based cohort study. BfOG 2013;120:1490-8.

6. O'Brien B, Chalmers B, Fell D, et al. The experience of pregnancy and birth with midwives: results from the Canadian Maternity Experiences Survey. Birth 2011;38:207-15

7. McDonald SD, Pullenayegum E, Chapman B, et al. Prevalence and predictors of exclusive breastfeeding at hospital discharge. Obstet Gynecol 2012;119:1171-9.

8. Darj E, Stålnacke B. Very early discharge from hospital after normal deliveries. Ups 7 Med Sci 2000;105:57-66.

9. Darling EK, Guttmann A, Sprague AE, et al. Implementation of the Canadian Paediatric Society's hyperbilirubinemia guidelines: a survey of Ontario hospitals. Paediatr Child Health 2014;19:133-7.

10. Watt S, Sword W, Krueger P. Longer postpartum hospitalization options Who stays, who leaves, what changes? BMC Pregnancy Childbirth 2005;5:13.

11. Darling EK, Ramsay T, Sprague AE, et al. Universal bilirubin screening and health care utilization. Pediatrics 2014;134:e1017-24.

12. Guidelines for detection, management and prevention of hyperbilirubinemia in term and late preterm newborn infants ( 35 or more weeks' gestation) - summary. Paediatr Child Health 2007;12:401-18.

13. Quality-Based Procedures clinical handbook for hyperbilirubinemia in term and late pre-term infants ( $\geq 35$ weeks). Toronto: Provincial Council for Maternal \& Child Health \& Ministry of Health and Long-Term Care; 2013.

14. Discharge Abstract Database metadata. Ottawa: Canadian Institute for Health Information; 2020. Available: https://www.cihi.ca/en/discharge-abstract-data base-metadata (accessed 2020 Feb. 2).

15. Registered Persons Database (RPDB). Government of Ontario; 2017. Available: https://data.ontario.ca/dataset/registered-persons-database-rpdb (accessed 2020 Feb. 20)

16. Data Dictionary: data repository. ICES; 2020. Available: https://datadictionary. ices.on.ca/Applications/DataDictionary/Default.aspx (accessed 2020 Feb. 20).

17. Weiss M, Ryan P, Lokken L, et al. Length of stay after vaginal birth: sociodemographic and readiness-for-discharge factors. Birth 2004;31:93-101.

18. Seaton SE, Barker L, Jenkins D, et al. What factors predict length of stay in a neonatal unit: a systematic review. BM7 Open 2016;6:e010466.

19. Wilkins R, Peters PA. PCCF+ version 5K user's guide: automated geocoding based on the Statistics Canada postal code conversion file. Ottawa: Statistics Canada; 2011. Cat no 82F0086-XDB.

20. Matheson FI, van Ingen T. 2016 Ontario Marginalization Index: user guide. Toronto: St. Michael's Hospital; 2018 [joint publication with Public Health Ontario]. Available: https://www.publichealthontario.ca/-/media/documents/ on-marg-userguide.pdf?la=en (accessed 2019 July 10).

21. Kehler S. Hyperbilirubinemia of the newborn: an investigation of midwifery practice [lecture]. Association of Ontario Midwives Midwifery Research Symposium; 2017 Nov. 13; Hamilton (ON).

22. Metcalfe A, Mathai M, Liu S, et al. Proportion of neonatal readmission attributed to length of stay for childbirth: a population-based cohort study. BMF Open 2016;6:e012007.

23. Policy statement: Early discharge and length of stay for term birth: a joint policy statement by the Canadian Paediatric Society and the Society of Obstetricians and Gynaecologists of Canada. SOGC Dec 1996;1281-5.
Available: https://www.jogc.com/article/S0849-5831(16)30285-3/pdf (accessed 2019 July 10).

24. Lemyre B, Jefferies AL, O'Flaherty P. Facilitating discharge from hospital of the healthy term infant. Paediatr Child Health 2018;23:515-31.

25. Canadian Hospitals Maternity Policies and Practices Survey. Ottawa: Public Health Agency of Canada; 2012.

26. Liu S, Wen SW, McMillan D, et al. Increased neonatal readmission rate associated with decreased length of hospital stay at birth in Canada. Can 7 Public Health 2000;91:46-50.

27. Darling E. Early hospital discharge of Ontario midwifery clients: trends over time [lecture]. McMaster Midwifery Research Symposium; 2019 Mar. 26; Hamilton (ON).

28. Benahmed N, San Miguel L, Devos C, et al. Vaginal delivery: How does early hospital discharge affect mother and child outcomes? A systematic literature review. BMC Pregnancy Childbirth 2017;17:289.

29. Biró MA, Waldenström U, Pannifex JH. Team midwifery care in a tertiary level obstetric service: a randomized controlled trial. Birth 2000;27:168-73.

30. Butler M, Collins R, Drennan J, et al. Hospital nurse-staffing models and patient- and staff-related outcomes. Cochrane Database Syst Rev 2019;(4): CD007019.

31. Hutton EK, Reitsma AH, Kaufman K. Outcomes associated with planned home and planned hospital births in low-risk women attended by midwives in Ontario, Canada, 2003-2006: a retrospective cohort study. Birth 2009;36: 180-9.

32. Hutton EK, Cappelletti A, Reitsma AH, et al. Outcomes associated with planned place of birth among women with low-risk pregnancies. CMAJ 2016; 188:E80-90.

Affiliations: Department of Obstetrics \& Gynecology (Darling) McMaster University; McMaster Midwifery Research Centre (Darling), McMaster University, Hamilton, Ont.; ICES (Babe, Perez), Hamilton, Ont.; Midwifery Education Program (Sorbara), Ryerson University; Institute of Health Policy, Management and Evaluation (Sorbara), University of Toronto, Toronto, Ont.

Contributors: Elizabeth Darling conceived and designed the study, and acquired the data. Glenda Babe and Richard Perez contributed to the study design. Glenda Babe analyzed the data. Elizabeth Darling, Carla Sorbara and Richard Perez interpreted the data. Elizabeth Darling and Glenda Babe drafted the manuscript. All of the authors revised the manuscript critically for important intellectual content, approved the final version to be published and agreed to be accountable for all aspects of the work.

Funding: This study was supported by ICES, which is funded by an annual grant from the Ontario Ministry of Health and Long-Term Care. Elizabeth Darling was supported by the Department of Obstetrics and Gynecology, McMaster University.

Data sharing: The data set from this study is held securely in coded form at ICES. Although data-sharing agreements prohibit ICES from making the data set publicly available, access may be granted to those who meet prespecified criteria for confidential access, available at www.ices.on.ca/ DAS. The full data set creation plan and underlying analytic code are available from the corresponding author on request, with the understanding that the programs may rely on coding templates or macros that are unique to ICES.

Acknowledgements: The authors acknowledge the contribution of Olivia Marquez in assisting with manuscript preparation and submission, and the contribution of Anastasia Gayowsky in conducting statistical analyses.

Disclaimer: This study was supported by ICES, which is funded by an annual grant from the Ontario Ministry of Health and Long-Term Care. The analyses, conclusions, opinions and statements expressed herein are solely those of the authors and do not reflect those of the funding or data sources; no endorsement is intended or should be inferred.

Supplemental information: For reviewer comments and the original submission of this manuscript, please see www.cmajopen.ca/content/8/2/ E462/suppl/DC1. 